\title{
Correction to: Cooperative game approach to form overlapping cloud federation based on inter-cloud architecture
}

\author{
Messaouda Ayachi ${ }^{1}$ (D) Hassina Nacer ${ }^{2} \cdot$ Hachem Slimani $^{3}$
}

Published online: 30 March 2021

(C) Springer Science+Business Media, LLC, part of Springer Nature 2021

\section{Correction to: Cluster Computing https://doi. org/10.1007/s10586-021-03253-z}

After Online Publication of the article [1] the authors noticed error in the labels of part Figures 12 to 24 and replaced the figures with revised version. Correct Figs. 12, $13,14,15,16,17,18,19,20,21,22,23$, and 24 are listed below

The original article can be found online at https:// doi.org/10.1007/s10586-021-03253-z.

The original article has been corrected.

Messaouda Ayach

messaouda.ayachi@univ-bejaia.dz

Hassina Nacer

sino_nacer@yahoo.fr

Hachem Slimani

hachem.slimani@univ-bejaia.dz

1 Département d'Informatique, Faculté des Sciences Exactes, Université de Bejaia, 06000 Bejaia, Algeria

2 Department of Computer Science, University of Sciences and Technologies Houari Boumedienne Algiers, Bab Ezzouar, Algeria

3 LIMED Laboratory, Department of Computer Science, University of Bejaia, 06000 Bejaia, Algeria 

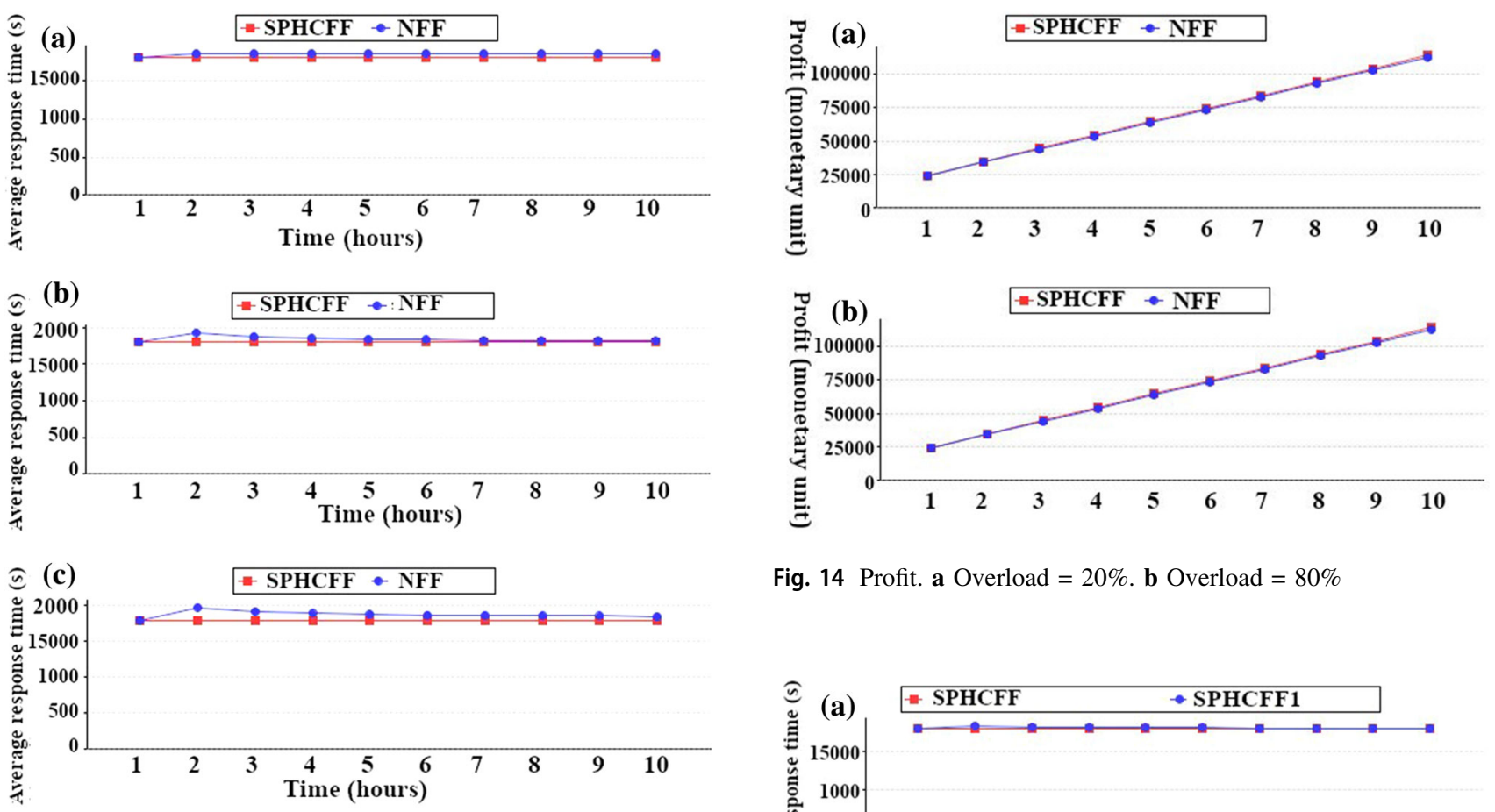

Fig. 12 Average response time. a Overload $=20 \%$. b Overload $=$ $60 \%$. c Overload $=80 \%$

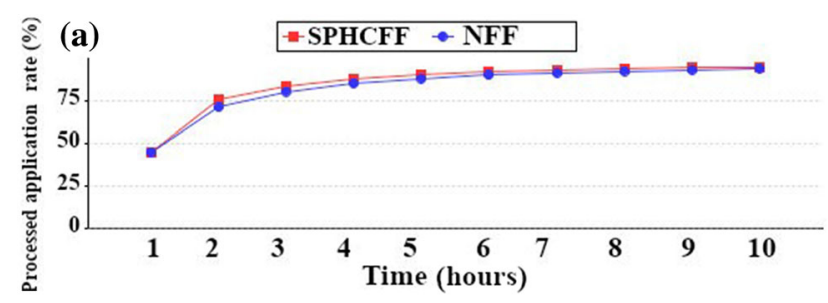

Fig. 14 Profit. a Overload $=20 \%$. b Overload $=80 \%$
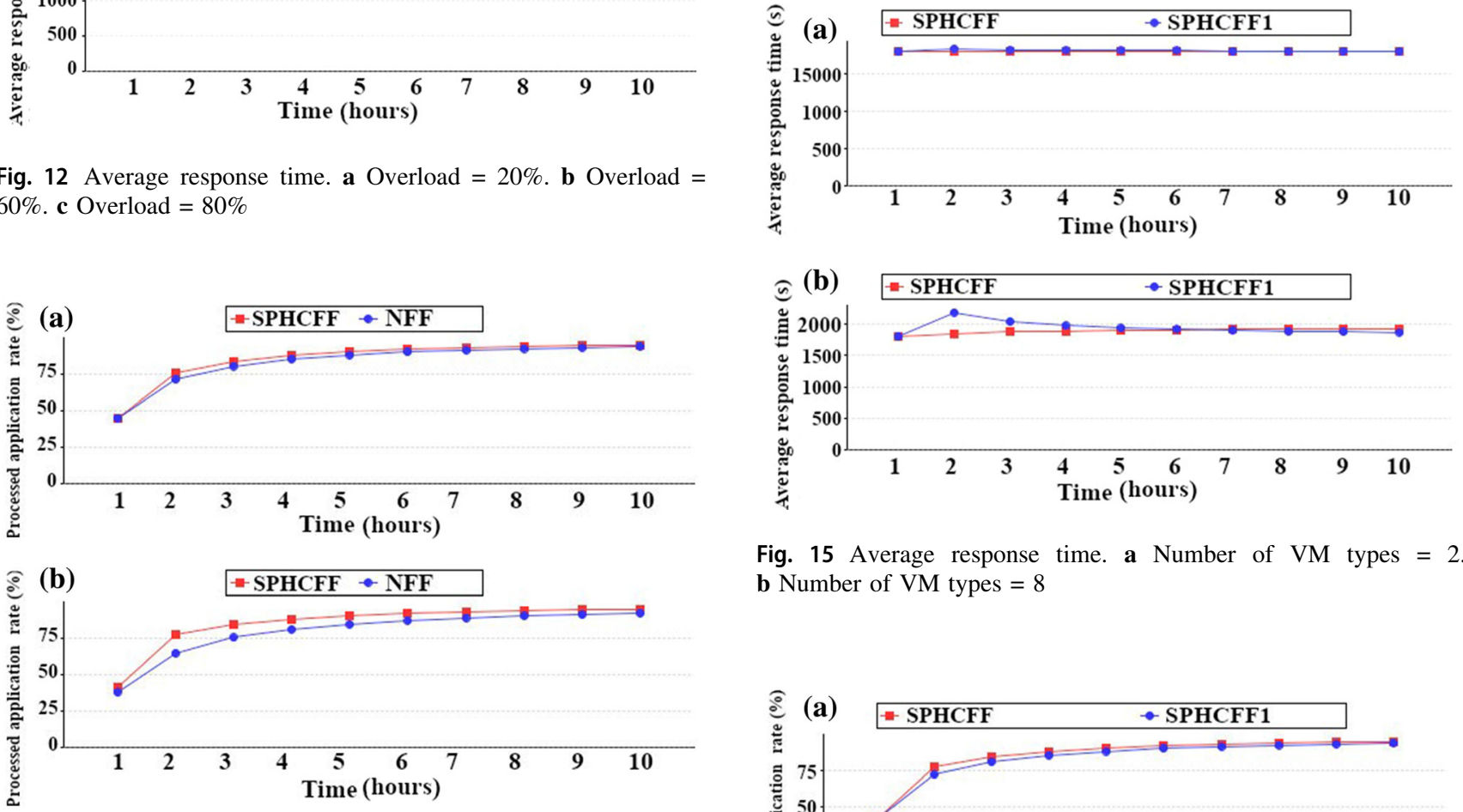

Fig. 15 Average response time. a Number of $\mathrm{VM}$ types $=2$. b Number of VM types $=8$
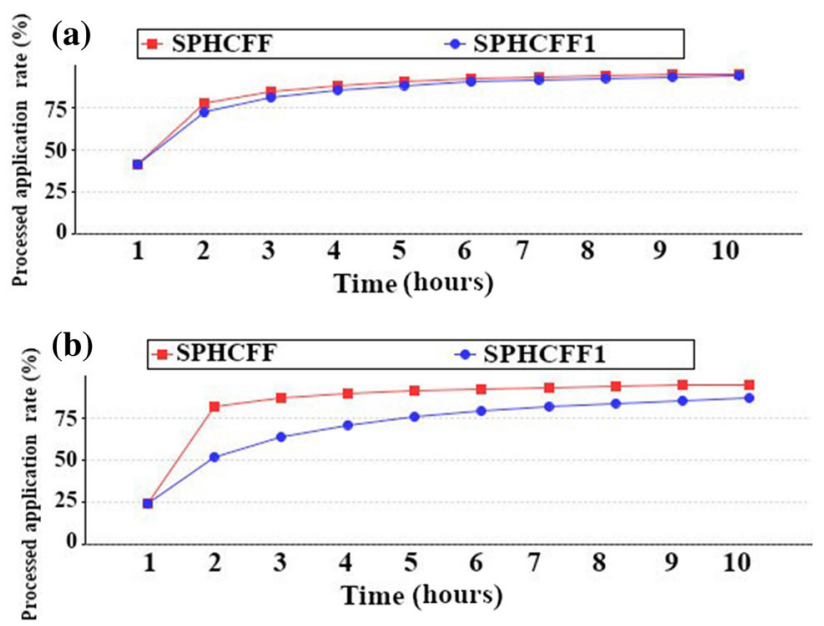

Fig. 16 Processed application rate. a Number of VM types $=2$. b Number of VM types $=8$ 

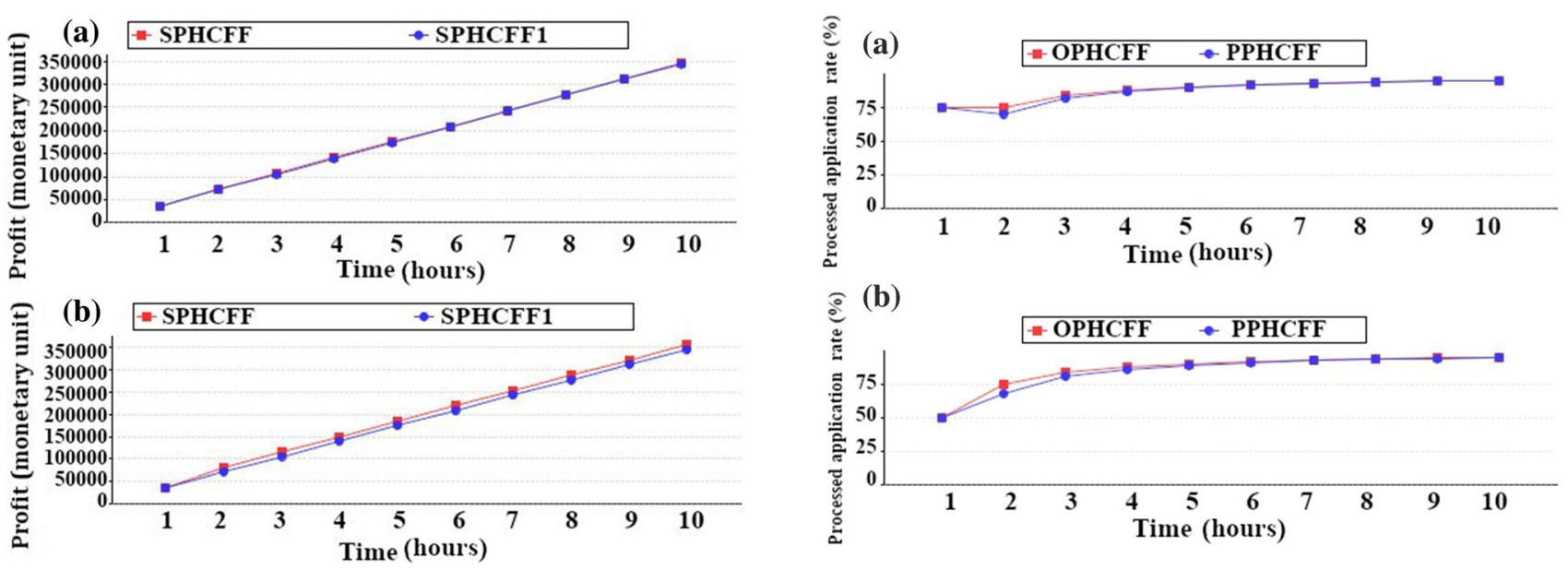

Fig. 17 Profit. a Number of VM types $=2$. $\mathbf{b}$ Number of VM types $=8$
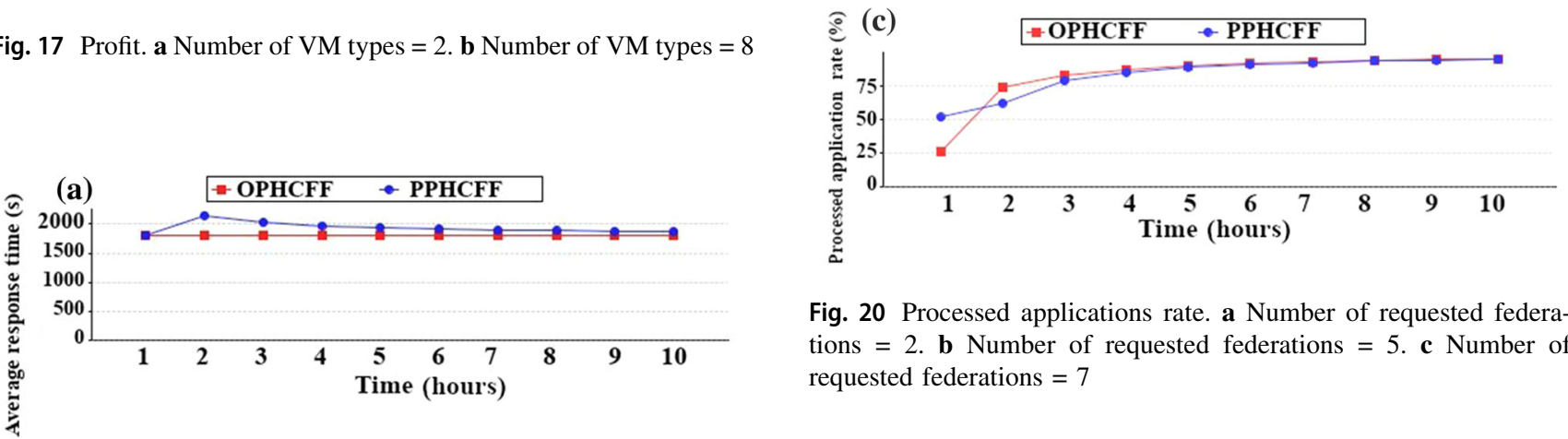

Fig. 20 Processed applications rate. a Number of requested federations $=2$. $\mathbf{b}$ Number of requested federations $=5$. $\mathbf{c}$ Number of requested federations $=7$
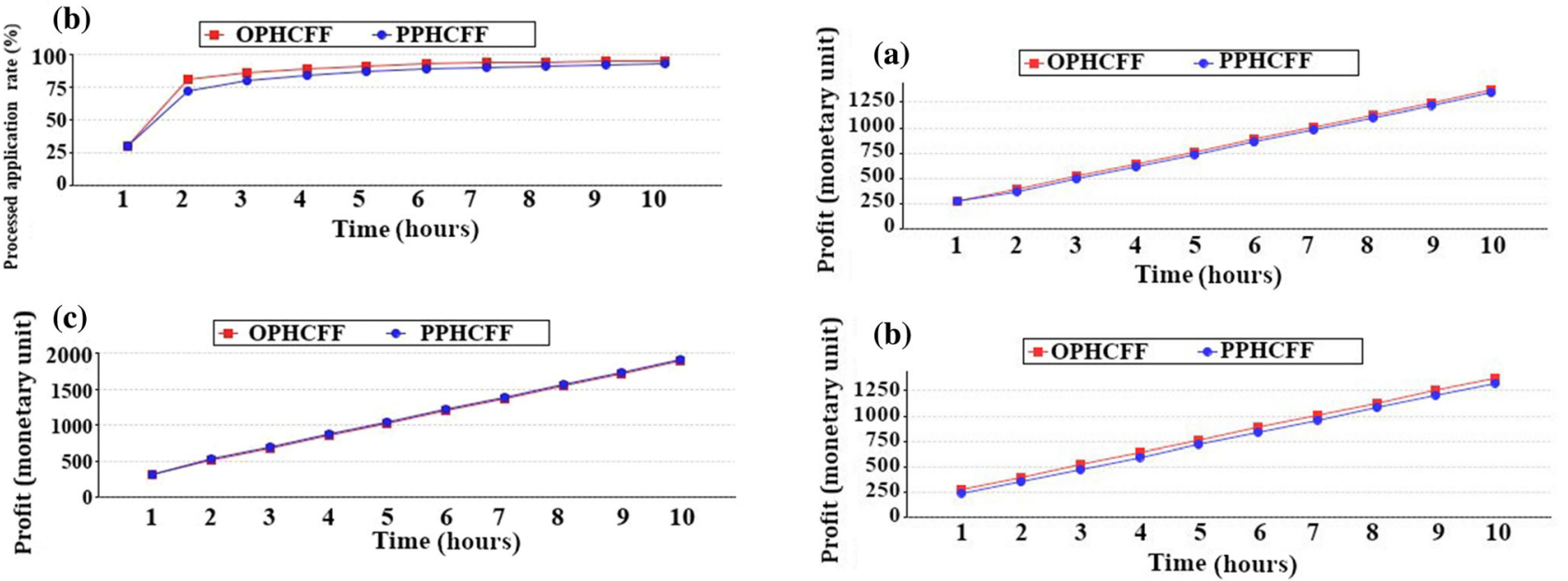

Fig. 18 Manager cloud (Cloud 1). a Average response time. b Processed application rate. c Profit

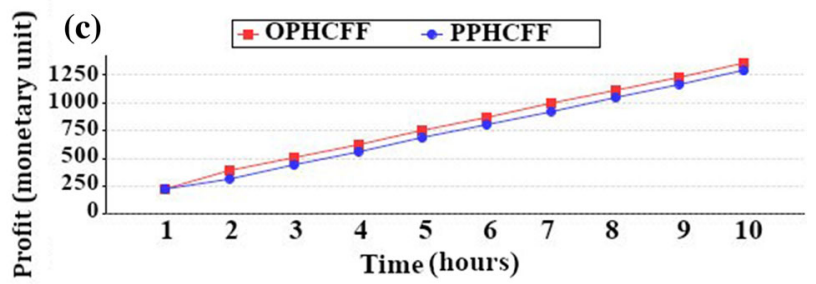

Fig. 21 Profit. a Number of requested federations $=2$. b Number of requested federations $=5$. $\mathbf{c}$ Number of requested federations $=7$

Fig. 19 Average response time (number of requested federations $=2$, $5,7)$ 


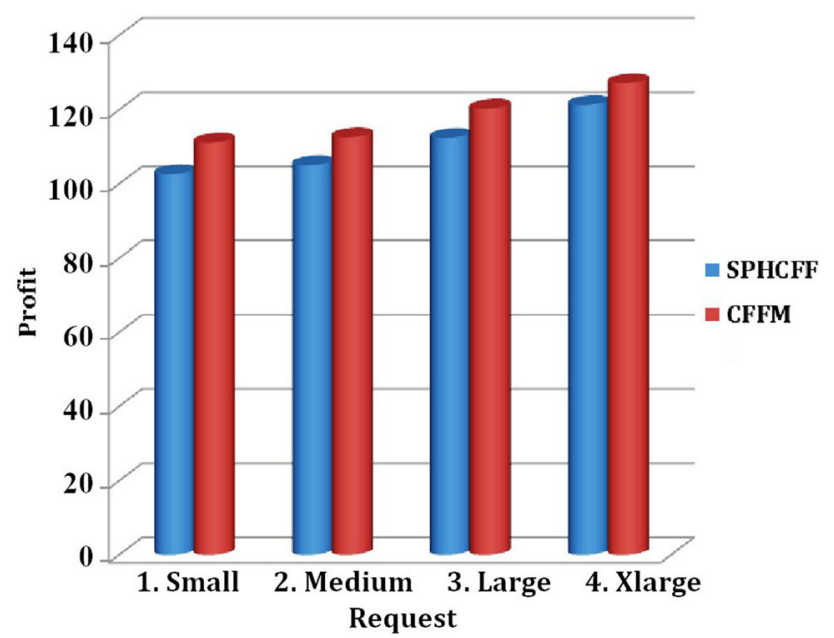

Fig. 22 Total profit of the cloud federation

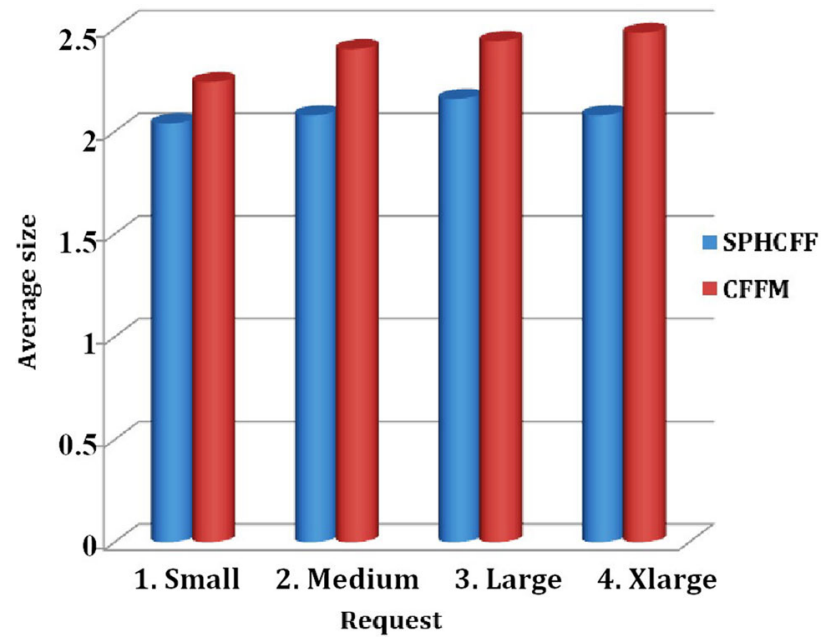

Fig. 23 Average size of the cloud federation

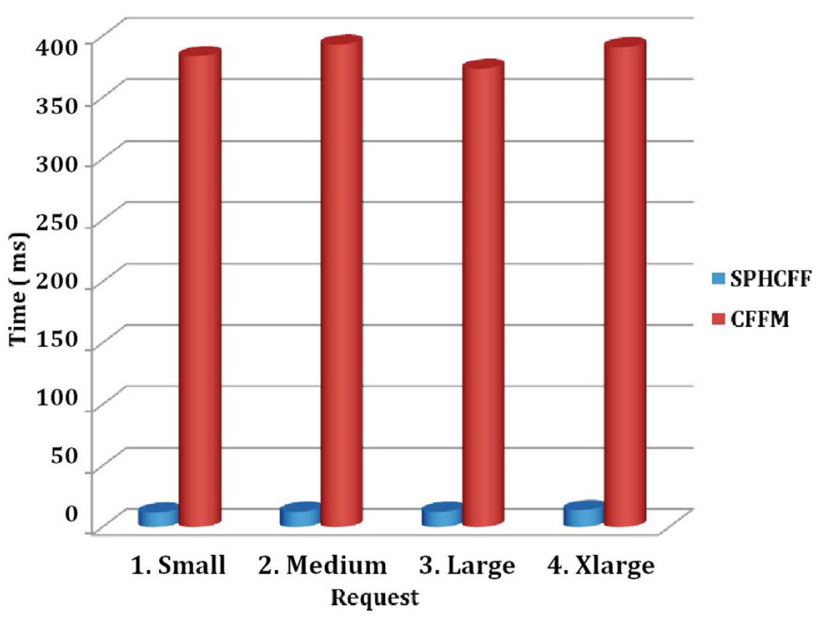

Fig. 24 Average execution time of the cloud federation formation mechanism

\section{Reference}

1. Ayachi, M., Nacer, H., Slimani, H.: Cooperative game approach to form overlapping cloud federation based on inter-cloud architecture. Cluster Comput (2021). https://doi.org/10.1007/s10586-02103253-z

Publisher's Note Springer Nature remains neutral with regard to jurisdictional claims in published maps and institutional affiliations. 